Historic, Archive Document

Do not assume content reflects current scientific knowledge, policies, or practices. 



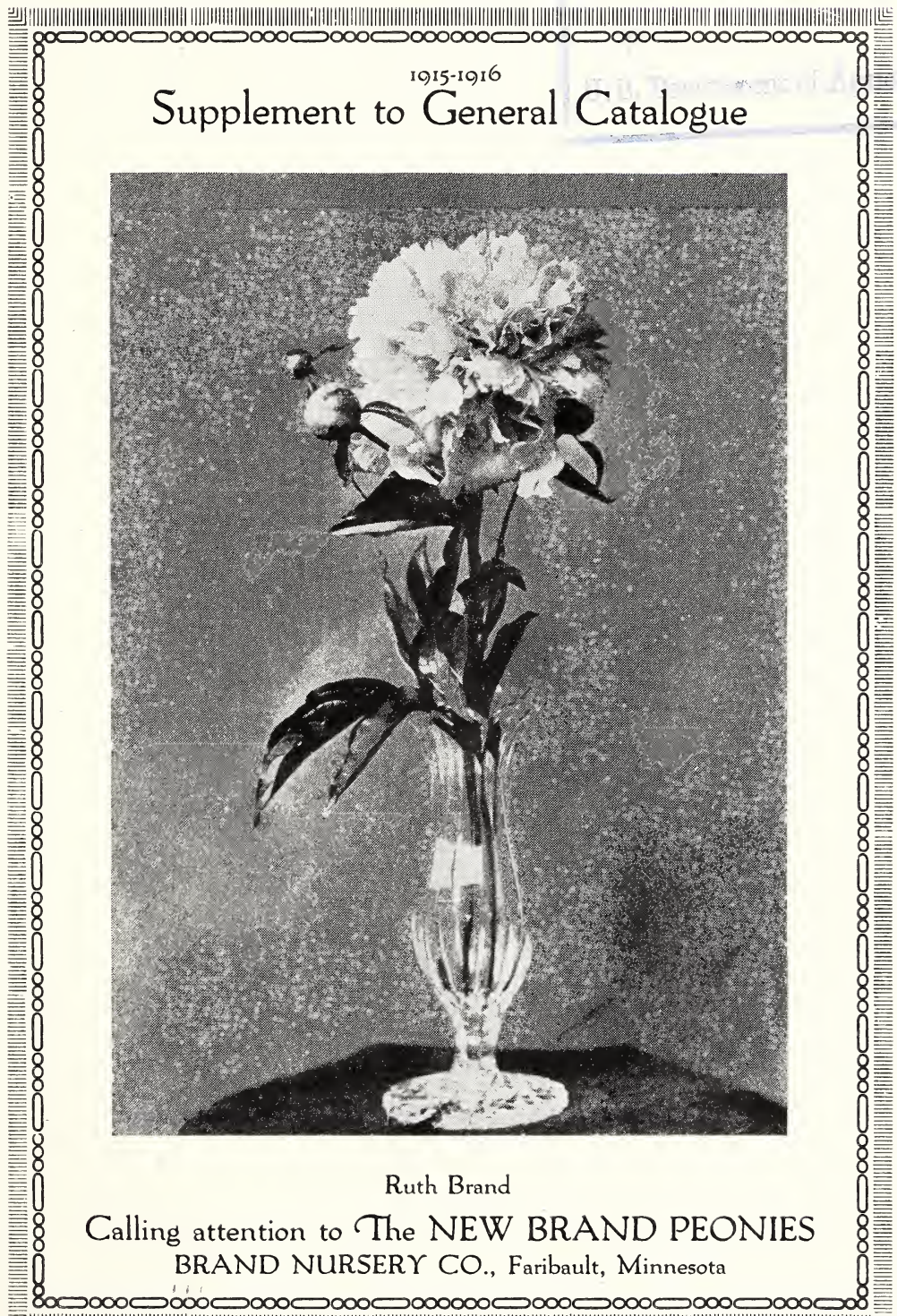

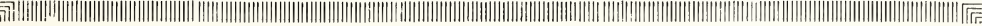





\section{The Brand Peonies}

At the time of getting out our General Peony Catalog in the early spring of 1913 , we did not fully appreciate what we really had in the Brand Peonies. By the Brand Peonies we mean those originated by Mr. O. F. Brand.

After selecting the best of these varieties from the seed bed in 1903 and 1904, they were tried out as to their bloom-. ing qualities for three years. This was necessarily done in a small way, as we had but one plant of each sort to begin with. After these first three years, all our desirable varieties were used exclusively for rapid propagation of the roots. Time was not given the varieties to blossom, as the roots were not allowed to stand over a year before being again lifted and replanted. By 1913 we had so increased our stock as to be able to allow quantities of each sort to again stand for bloom.

We are surprised at the marvelous beauty of what we have. Born and reared for years among peonies, and having seen all but the most recent of all the peonies of the world, placed us in a position to appreciate the fact that Mr. Brand had produced here at Faribault in Martha Bulloch, the most wonderful and extravagantly beautiful of all peonies, and that in many others of his varieties, this sort was almost equalled.

Of late years we have been testing the best of the new Old World sorts as they come out, and although many of them are wonders of the Hybridizer's art, we find none better than a score of varieties produced in our own beds, with our American sorts having the advantage of being propagated in the almost virgin soil of Minnesota, which gives us a strong, robust plant, 
with roots entirely free from the French Root. Disease which we see on so many of the new varieties coming from across the water.

At the Summer Meeting of 1913 of the Minnesota State Horticultural Society, the largest society of its kind in the world, we showed seven varieties of our new creations. On these we received four prizes-first, second, third and fourth. Of these varieties, the first prize peony was Martha Bulloch. We displayed a vase of three blooms, and this vase was the center of attraction of the entire peony show. Many thought Mary Brand, Chestine Gowdy, Francis Willard and Archie Brand nearly as good.

At the summer meeting, 1914, of the same society, we showed twenty-seven varieties of our own creations and again took all prizes offered in this class. Of this display the secretary, in his report of the show, says:

"All four premiums offered for seedlings went to this exhibit, which contained some marvelous sorts, surpassing in color, texture and size, anything the writer had ever previously seen. It was a very interesting feature of the exhibit."

Again at the summer meeting, 1915, with fully twice the number of flowers on exhibit as the year before, we displayed eighteen varieties of seedlings and took all prizes offered in this class.

The secretary of the society, in his report of this show, says:

"Considering the character of the season the exhibit was certainly a marvel. A large display was anticipated, as entries had been made in number nearly twice as many as the year before, approximating 500. The principal display consisted of collections of single vases of peonies, hundreds of which were shown, filling several long tables, which were set out in the farm dining hall. There were two professional collections of peonies, aggregating hundreds of varieties. Two much cannot be said of the beauty of this display, but as our readers are all familiar with the wonderful charm of this particular flower, imagination must supply what is needed that the reader may appreciate the character of this exhibit. There was only one 
display of Seedling Peonies, from the Brand Nursery Company, of Faribault, but in this display there were a number of very beautiful varieties, some of them unsurpassed, as far as the writer could judge, by any heretofore grown and distributed commercially. Four awards were made to this collection."

Speaking of this same show, we clip from the St. Paul Dispatch of Tuesday, June 22:

"Festoons of peonies of a dozen different choice varieties and hundreds of others of less select species, were the center of attraction at the summer meeting of the Minnesota State Horticultural Society, which opened today at the Minnesota College of Agriculture.

"The horticulturists met in joint session with the Minnesota State Garden Flower Society, the Minnesota State Beekeepers' Association and the State Florists' Society.

\section{SHOW 175 VARIETIES.}

"St. Paul was represented by the Hoyt Nursery and D. W. C. Ruff. The Ruff exhibit had the largest variety of peonies entered, with 175 varieties.

"The Hoyt Nursery had the next largest number of varieties at the exhibit-150.

\section{CHOOSE FOUR OUT OF 100,000.}

"The Brand seedling' peonies from the Brand Nursery at Faribault, contained four of the choicest varieties in the show. From more than $1,000,000$ peony seeds, which developed 100,000 blossoming plants, four choice varieties were singled out for head-liners at the peony show. They were called the Martha Bullock, named after President Roosevelt's mother. Frances Willard, Mary Brand and Chestine Gowdy. Martha Bullock roots are selling at the fancy figure of $\$ 15$ each, and it is impossible to supply the demand, it was said."

At the summer meeting, 1905, of this same society, we displayed three varieties of our own creations and took first, second and third prizes.

This summer meeting is generally held at a date later than the 16 th of June, at which time our own early varieties 
and medium varieties are gone, and we have been able to display only late sorts, as we have displayed, so far, only direct from the field. This accounts for the most of our best varieties having never been on display at our Minnesota show.

Three years more of testing our new varieties upon an ever enlarging scale, has only tended to strengthen our belief in their quality and of these varieties for the season of 1914-15 we wish to call special attention.

AMANDA YALE, 2nd prize, 1905. A splendid milky white flower with carmine blotches.

ARCHIE BRAND (1913), 1st prize, 1905. A beautiful flower of the bomb type. A delicate lavender pink. One of our best.

CHESTINE GOWDY (1907), 4th prize, 1914. A large flower of delicate and varied colors. A flower that has always received much favorable comment wherever shown.

FRANCES WILLARD (1907), 3rd prize, 1913. Without exception this is the most satisfactory white we know of. Strong, robust habit. Heavy bloomer. Always good.

We recently received a letter from a great peony lover who has an immense collection. In this letter he says: "I have most of the best of the world's peonies. I consider your. peony, Frances Willard, the finest peony in the world."

JUDGE BERRY (1907) (early, never shown). Next to Martha Bulloch we consider this our most wonderful kind. A flower of rare, delicate and fascinating beauty. Opening delicate sea-shell pink and fading to white. Should be in every collection.

LONGFELLOW (1907) (medium early, never shown). An exceptionally fine red. We know of no brighter or more pleasing red in the peony world.

LORA DEXHEIMER (1913), 1st prize, 1915. Another fine red. The only red of its type that we have. Strictly firstclass.

MARTHA BULLOCH (1907), 1st prize, 1913. We cannot 
be too extravagant in our praise of this flower. Unquestionably the finest peony in cultivation. An immense pink of soft and pleasing shade, produced on long, stiff stems. Plant at four years of age will not have more than seven or eight stems, but each stem will produce one, and, as a rule, only one large, perfect flower, which is pronounced by everyone who sees it as the most wonderful peony they have ever seen. Mons. Jules Elie is a wonderful pink, but it is simply not in the running when compared to this wonderful sort.

The sensation of the 1913, 1914 and 1915 flower shows. Stock very limited. Not more than one plant will be furnished a party.

MARY BRAND (1907), 2nd prize peony, 1913. Shown only in comparison with Martha Bulloch, that vareity receiving first prize and Mary Brand second. Far and away the best of all reds everything considered. A flower of immense size, of a deep, pleasing, bright red color. Plant strong and robust. Prodigal in the amount of bloom produced.

MIDNIGHT (1907). “The Black Peony.” Not really black, but the darkest peony we have ever seen.

PRINCE OF DARKNESS (1907) (never shown). Almost as good as Midnight.

RICHARD CARVEL (1913) (very early, never shown). The best dark early red in cultivation. As good a red as Mons. Jules Elie is a pink, and of the same type. The first seedling peony to bloom that Mr. Brand produced. In its color and season, never beaten.

WILLIAM PENN (1907) (never shown). This flower is the largest variety we have produced. Many of the larger peonies are coarse, but this is not. Always selected as a desirable variety. Color, rose, changing to pink. Must be supported to keep its immense blossoms off the ground.

WINNIFRED DOMME (1913) (never shown). Another very striking first-class mid-season, bright dark red. Stock limited. Not more than one to a person.

FLORENCE NIGHTINGALE (1907), 4th prize, 1913. Left 
out of our catalog by mistake. A spléndid, very late white. A dainty variety and in bloom when all other whites are gone.

ELIZABETH BARRETT BROWNING. Rose type, very late. A tall, commanding variety with foliage strikingly clean, large and glossy. A wonderful flower. Buds of immense size of a delicate pink shade with a splashing of carmine as in the variety LaTulip, gradually open into wondrous large flowers of the purest white, with occasional dashes of carmine on the petals. Its immense size, its large and prominent guard petals; its loosely filled center of broad and narrow petals curiously intermingled, the striking pureness of its color make a beauty combination pen cannot describe. One of the most delightfully fragrant peonies ever created. This variety was sold by us upon its introduction at $\$ 25$ per root.

The foregoing is the cream of Mr. Brand's productions which we have in large enough quantities to justify us in urging the sale of for this season.

We have had quite a number of inquiries for our first prize flower, 1914. This flower we have named "Desire." It will not be offered for sale for some years.

We are constantly bringing out new varieties, the product of the most careful crossing of desirable sorts about ten thousand seeds being planted each year. The foregoing are the best of over 200,000 seedlings produced.

We do not issue a catalog every year, as this is not necessary, as we carry about the same stock from year to year. But since issuing our last catalog, which we are sending or have sent you, our stock in many varieties of our new peonies has greatly increased. This causes us to change the price of some varieties for the season 1914 and 1915, as follows:

Amanda Yale $\$ 1.00$

Longfellow 7.00

Archie Brand 10.00

Aunt Ellen

Benjamin Franklin

Charles McKellip

Chestine Gowdy.

Little Sweetheart

Martha Bulloch. 15.00 Mary Brand.................. 7.00

Midnight 2.00

Richard Carvel 1.00 
Darkness

Ruth Brand.................... 1.00

Ella Wheeler Wilcox.... 3.00

William Penn................. 1.00

Frances Willard............ 10.00

Winnifred Domme........ 5.00

Harriet F. Reddick...... 1.00

Florence Nightingale.... 2.00

Judge Berry..................... 10.00

Elizabeth B. Browning 10.00

Leona Kinney

1.00

The "Brand Peonies" have been exhibited four times. They have won:

Minnesota State Horticultural Society, Summer Meeting: 1905-1st, 2nd, 3rd.

1913-1st, 2nd, 3rd, 4th.

1914-1st, 2nd, 3rd, 4th.

1915-Ist, 2nd, 3rd, 4th.

You should get some of these new varieties and get something your neighbors do not have.

The foregoing list of our very best peonies amounts to $\$ 105.00$.

The list will be furnished entire for $\$ 80.00$.

\section{BRAND'S HYBRID DELPHINIUM.}

We started several years ago with a very select strain of Delphinium. We have carefully selected for the most beautiful varieties year after year, until we now have a strain the equal of any. The seed of the Delphinium does not breed true, but our stock is so well bred up that the seed from it can be relied on to produce something exceptionally fine. We are offering some very carefully selected seed from our choicest plants at 15 cents per large package, postpaid. 

y 
the REPUBLICAN PRESS

FARIBAULT, - MINNESOTA 